\title{
Epistemic adverbs that can/cannot be embedded under imperatives
}

\author{
Yuto Hirayama \& Shun Ihara*
}

\begin{abstract}
This paper analyzes why certain epistemic adverbs are/are not embeddable under imperatives, by adopting Kaufmann's (2012) modal analysis of imperatives and the assumption that epistemic modal bases are closed. The embeddable adverb is a modal modifier (Anand \& Brasoveanu 2009) that expands the quantificational domain of the modal co-occurring with it, but the unembeddable one is a pure epistemic modal whose semantics does not involve an ordering source as in von Fintel \& Gillies (2010). Imperative operators lose their contribution when they scope over the latter type adverbs because of vacuous quantification, hence violating a conversational principle proposed by Crnič (2011). The account lends support to the modal analysis of imperatives, which competes with Portner's (2007) To-Do Lists analysis.
\end{abstract}

Keywords. imperatives; epistemic adverbs; deontic modals

1. Introduction. This paper deals with an issue that has gone unnoticed in the literature: why is a certain class of epistemic adverbs embeddable under imperatives, while another class is not? Specifically, Japanese has two epistemic adverbs, zettaini 'definitely' and matigainaku 'certainly'. ${ }^{1}$ They convey an almost identical meaning when they occur in declaratives:

(1) Kare-wa zettaini/matigainaku isha-da.

he-TOP definitely/certainly doctor-COP

'He is definitely/absolutely a doctor.'

In (1), both adverbs are interpreted as conveying epistemic modality. However, the two adverbs differ when embedded under imperatives:

(2) Ringo-o zettaini/\#matigainaku taber-o.

apple-ACC definitely/\#certainly eat-IMP

'Definitely/Certainly eat an apple!'

The zettaini-version is interpreted as posing a stronger command than the plain imperative (i.e., zettaini strengthen the command offered by the speaker), while matigainaku is incompatible with imperatives in the first place. How can we derive this contrast?

Our argument is that we can capture the contrast if we adopt two assumptions available in the market: the modal approach to imperatives (Kaufmann 2012) and the closedness of the

${ }^{*}$ We are grateful to Eri Tanaka, Kenta Mizutani, Lisa Matthewson, Hotze Rullmann, Marcin Morzycki, Neda Todorovic, Hiroshi Mito, Kenshi Funakoshi, Uli Sauerland, and UBC TAP-LAB members for their constructive comments. We also thank the audience at LSA 93rd meeting. Of course, all remaining errors are our own. This research has been supported by Japan Society for the Promotion of Science (JSPS) KAKENHI (17J03552). Authors: Yuto Hirayama, Osaka University/JSPS Research Fellow (yuto.hirayama.111@gmail.com) \& Shun Ihara, Osaka University/JSPS Research Fellow (iharashun0@gmail.com).

${ }^{1}$ Matigainaku is in fact ambiguous between its epistemic interpretation exemplified in (1) and its decompositional meaning, which roughly corresponds to 'without making mistakes'. The latter interpretation comes from the fact that matigainaku can be decomposed into matigai 'mistake' and naku 'NEG'. We deal only with the former interpretation throughout this paper. 
context set (i.e. the epistemic modal base) (Gillies 2010 and von Fintel \& Gillies 2010). We will propose that zettaini is a modal modifier as in Anand \& Brasoveanu 2009 while matigainaku is a pure epistemic modal without ordering sources. The imperative operator contains the context set as its quantificational domain, and its contribution is lost when it scopes over matigainaku-type adverbs because of the closedness, leading to violation of a conversational principle proposed by Crnič (2011).

The rest of this paper is structured as follows. Section 2 introduces Kaufmann's (2012) modal analysis of imperatives. Section 3 discusses the validity of the closedness of the context set. Section 4 gives observations and analyses on the semantics of zettaini and matigainaku. Section 5 illustrates how the contrast in (2) is derived, and Section 6 is the conclusion with an implication for the controversy between the modal approach to imperatives and the To-Do Lists approach proposed by Portner (2007).

2. A modal view of imperatives. Imperatives have recently been argued to belong to modality proper, in that a modal operator is responsible for their conventional link to directive speech acts (Han 1998, Grosz 2009, Kaufmann 2012, Condoravdi \& Lauer 2012, Medeiros 2013, Ihara \& Noguchi 2019, a.o.). Before we spell out the analysis in detail, in this section, we introduce the framework that we adopt for the analysis, which is generally known as the "modal theory" (or the "strong theory") of imperatives developed by Kaufmann (2012).

Kaufmann's theory relies on a version of Kratzer's (1981) semantics for modality in possible worlds semantics. Kratzer employs conversational backgrounds, which are functions from worlds to sets of propositions that describe what is known to an agent, what is desired by an agent, what the law says, etc. Modal expressions can then be interpreted as quantifiers over the sets of possible worlds compatible with such a background (i.e. the intersection of the set of propositions that the conversational background assigns to the world of evaluation). She further proposes to individuate the domain of quantification via two conversational backgrounds that play different roles: one serves as the modal base (represented as ' $f$ ') that records 'what is known' or 'what the relevant facts are'; the other one serves as the ordering source (represented as ' $g$ ') and determines which of the worlds compatible with these relevant facts are more plausible, are morally better, realize more of an agent's goals, etc. Technically, the ordering source induces an ordering on the set of possible worlds ' $\preceq_{g(w)}$ ' as in (3), which is used to single out the highest ranked worlds among those compatible with the modal base: 'BEST $(f)(g)(w)$ ' are those worlds in $\bigcap f(w)$ such that no other worlds in $\bigcap f(w)$ are strictly better than they are according to $g(w)$, cf. (4).

$$
\begin{aligned}
& u \preceq_{g(w)} v \text { iff }\{p \mid p \in \bigcap g(w) \wedge v \in p\} \subseteq\{p \mid p \in \bigcap g(w) \wedge u \in p\} \\
& \left.\operatorname{BEST}(f)(g)(w)=\left\{w^{\prime} \mid \forall z \in \bigcap f(w)\left[z \preceq_{g(w)} w^{\prime} \rightarrow w^{\prime} \preceq_{g(w)} z\right)\right]\right\}
\end{aligned}
$$

By adopting Kratzer's framework of modals, Kaufmann derives the meaning of imperatives from a modal layer in the semantics of imperatives, i.e., imperatives have almost the same truth-condition as sentences with deontic modals like should or ought to, which allows us to analyze imperatives on a par with deontic modals. She proposes that the relevant modal base is what is known to the conversational participants, that is, the Common Ground $(C G)$, 
whose intersection is the Context Set $(C S)$, and that the ordering source is deontic. ${ }^{2}$ The following is a simplified denotation of Kaufmann's imperative operator, where $c_{A}$ is the addressee in the context of the utterance. ${ }^{3}$

$$
\llbracket O P_{\text {imp }} \rrbracket=\lambda f \lambda g \lambda p \lambda w . \forall w^{\prime}\left[w^{\prime} \in \bigcap f(w) \cap \operatorname{BEST}(f)(g)(w) \rightarrow p\left(w^{\prime}\right)\right],
$$
where $f(w)=C G(w)=\{p \mid p$ is known in $w\}$, and $g(w)=\{p \mid p$ is is what is ordered to $c_{A}$ in $\left.w\right\}$.

Let us briefly demonstrate how the meaning of imperatives is derived in Kaufmann's account. Consider (6) for example.

Come to the party!

【Come to the party! $\rrbracket=\forall w^{\prime}\left[w^{\prime} \in \bigcap f(w) \cap \operatorname{BEST}(f)(g)(w) \rightarrow c_{A}\right.$ comes to the party at $\left.w^{\prime}\right]$.

The imperative (6) is true iff the addressee comes to the party at all worlds $w$ in $C S$ (that is, $\left.\bigcap f\left(w^{\prime}\right)\right)$, and ranked best in terms of what the addressee is ordered to do at $w$. More intuitively, (6) is true iff the speaker and the addressee know that it is possible that the addressee comes to the party, and his/her coming to the party satisfies the greatest number of orders posed on the addressee among alternatives actions such as the addressee playing soccer, the addressee cleaning the room, etc.

We do not go into further details of her model due to limitations of space, but this line of analysis, namely the 'imperatives-as-modalized-propositions' analysis, works well enough to explain why epistemic adverbs like zettaini are embeddable in imperatives while ones like matigainaku are not.

3. The closedness of the context set. This section briefly introduces the notion of closedness. This is a property of the context set, which says that the set of epistemically accessible worlds are constant among worlds contained in that set. Formally:

$$
\text { If } w^{\prime} \in C S(w) \text {, then } C S\left(w^{\prime}\right)=C S(w) \text {. }
$$

This property is assumed by several analyses of epistemic modals (von Fintel \& Gillies (2010) and Gillies (2010), to name a few), and can be derived from two other properties of the context set that are more widely assumed in the modal literature (Kaufmann et al. 2006): realism and negative introspection. The rest of this section sees the validity of these two properties and how closedness is derived from them.

\footnotetext{
${ }^{2}$ Kaufmann expresses the meaning flexibility of imperatives (e.g. COMMAND, ADVISE, PERMISSION, etc.) by assuming that the value of the ordering source $g$ depends on contexts. Although we fix its value as COMMAND throughout this paper, the explanation we will propose is also applicable to other values.

${ }^{3}$ Kaufmann proposes that the imperative operator enforces the following presuppositions: (i) temporal restriction: an imperative is satisfied at or following utterance time, (ii) authority condition: the speaker is in an epistemically privileged position with respect to the conversational backgrounds $f$ and $g$, (iii) epistemic uncertainty: the speaker believes that both $p$ and $\neg p$ are possible, and (iv) ordering source restriction: the ordering source $g$ must be prioritizing or speaker bouletic, in the sense of Portner (2007). The semantics introduced here also ignores several complications and contains only notions relevant to the following discussion for the sake of simplicity, which makes no difference in the following discussion. For the complete version, refer to Kaufmann (2012, Ch. 3-4).
} 
3.1 REALISM. If the set of worlds accessible from a world $w$ is realistic, $w$ is itself contained in that set (in other words, the accessibility relation between $w$ and its accessible worlds is $r e$ flexive). It is generally held that the context set, that is, the set of worlds compatible with the knowledge of the speaker (or conversational participants), has this property. Thus, we have $w$ $\in C S(w)$. This property ensures that our world is the one where all known propositions are true. Therefore $k_{n o w}(p)$, which is assumed to be true at a world $w$ if $p$ is true in all worlds in $C S(w)$, entails the truth of $p$.

3.2 NegAtive introspection. If a set of worlds accessible from a world $w$ are negative introspective, in other words, if the accessibility relation involved is euclidean, that set is a subset of the set of worlds accessible from a world in that set. When $C S(w)$ has this property, we have $C S(w) \subseteq C S\left(w^{\prime}\right)$ for any $w^{\prime} \in C S(w)$.

What if $C S$ does not have this property? It allows the case where $w^{\prime} \in C S(w), w^{\prime \prime} \in C S\left(w^{\prime}\right)$, and $C S\left(w^{\prime}\right) \nsubseteq C S\left(w^{\prime \prime}\right)$, that is, some worlds in $C S\left(w^{\prime}\right)$ are not contained in $C S\left(w^{\prime \prime}\right)$. This means that $C S(w)$ can contain a $p$-world, which leads to $p$ might be true, while all worlds in $C S\left(w^{\prime}\right)$ are $\neg p$-worlds, which is equivalent to I know it is certain that $p$ is true, on the assumption that $\operatorname{might}(p)$ and it is certain $(p)$ are true at $w$ if there is a $p$-world in $C S(w)$ and if all worlds in $C S(w)$ are $p$-worlds, respectively. Thus we predict the continuation $p$ might be true but I know it is certain that $p$ is not true to be consistent, which is not.

3.3 Closedness. The closednness is logically derived from realism and negative introspection. Following is the proof steps adapted from Gillies (2010: 7):

(8) For any $w^{\prime} \in C S(w)$,

(i) Since $w^{\prime} \in C S(w)$, we have $C S(w) \subseteq C S\left(w^{\prime}\right)$ [Negative introspection].

(ii) Since $C S(w) \subseteq C S\left(w^{\prime}\right)$ and $w \in C S(w)$ [Realism], we have $w \in C S\left(w^{\prime}\right)$.

(iii) Since $w \in C S\left(w^{\prime}\right)$, we have $C S\left(w^{\prime}\right) \subseteq C S(w)$ [Euclidean].

(iv) Since $C S(w) \subseteq C S\left(w^{\prime}\right)$ and $C S\left(w^{\prime}\right) \subseteq C S(w)$, we have $C S(w)=C S\left(w^{\prime}\right)$.

Thus, for any $w^{\prime} \in C S(w), C S(w)=C S\left(w^{\prime}\right)$. Given that the two properties overviewed in the two preceding subsections are necessary to capture the behavior of epistemic modality and knowledge ascription like know, the closedness, which is a logical consequence of them, should be maintained.

4. Semantics of zettaini and matigainaku. This section proposes the semantics for the two adverbs zettaini and matigainaku. We analyze zettaini as a modal modifier (Anand \& Brasoveanu 2009) which takes a modal as one of its arguments, and matigainaku as a pure epistemic modal which accompanies no ordering sources as in von Fintel \& Gillies (2010).

4.1 Zettaini AS A MODAL MODIFIER. Although we call zettaini as an epistemic adverb, its interpretation is not strictly limited to the epistemic one. It concords with the modal with which it is co-occurring and strengthens the modal claim. The following is one piece of evidence for that:

(9) (At a pub, John is trying to order his and your drinks. He asks you "What do you want to drink?" You say) 

a. Watashi-wa zettaini biiru-ga nomi-tai.
I-TOP definitely beer-NOM drink-want.to
'I definitely want to drink beer.'
b. \#Watashi-wa biiru-ga nomi-tai nitigainai.
I-TOP beer-NOM drink-want.to must
'I must want to drink beer.'

As in (9-b), the epistemic modal nitigainai 'must' is odd in this context because the speaker is having direct experience of her current internal state (in this case, her internal desire to drink beer), so does not have to make an inference about it. The felicity of (9-a) means that zettaini is not offering epistemic modality in this case; it strengthens the bouletic statement made by -tai 'want.to'.

The modal flavor that zettaini can strengthen is not limited to the bouletic one; it goes also with volitional modality:

(10) (Yesterday you said an inappropriate thing to a friend. You regret it and you now have firm determination not to say such a thing. You say to yourself)
a. Watashi-wa zettaini nidoto anna-koto-o iwa-nai.
I-TOP definitely again that-thing-ACC say-NEG
'I will definitely not say that thing again.'
b. \#Watashi-wa nidoto anna-koto-o iwa-nai nitigainai.
I-TOP again that-thing-ACC say-NEG must EPISTEMIC
'I must not be going to say that thing again.'

(10-b) sounds odd for the same reason as in (9-b): the speaker need not infer what her current volitional state is like, while zettaini concords with the volitional modality served by the predicate yaru as in (9-a). ${ }^{4}$ These facts suggest that zettaini flexibly concords with a wide range of modals.

We propose, in line with Anand \& Brasoveanu (2009), that zettaini is a modal modifier that takes a modal as one of its arguments. Anand \& Brasoveanu deal with the fact that sentences like (11) involve two modals, the adverb obligatorily and the auxiliary must, but convey only one modal statement (the phenomenon known as modal concord), and argue that deontic modal adverbs such as obligatorily and legitimately share their contextual backgrounds with the modal co-occurring with them (the ordering source is abbreviated for the sake of simplicity, and $M$ is a variable over modals):

\footnotetext{
${ }^{4}$ In (9-a), one might find it unreasonable that the bare form yaru provides the volitional modality, and be tempted to claim that the modality comes from zettaini. However, the following shows that the bare form provides volitionality on its own in Japanese:

(i) (The same context as (10))

Watashi-wa kyoo yaru.

I-TOP today do

'I will do it today.'

Therefore, we assume that Japanese bare forms serve as modals in some cases, and that (10) and (i) are examples where it gives volitional modality.
} 
(11) John obligatorily must be home.

$$
\begin{aligned}
& \text { a. Structure: } \\
& \text { [[[obligatorily must }] f] p] \\
& \text { b. } \quad \llbracket m u s t \rrbracket=\lambda f \lambda p \lambda w . \forall w^{\prime}\left[w^{\prime} \in \bigcap f(w) \rightarrow p\left(w^{\prime}\right)\right] \\
& \llbracket \text { obligatorily } \rrbracket=\lambda M \lambda f \lambda p \lambda w: f \text { is deontic. } M(f)(p)(w) \wedge \forall w^{\prime}\left[w^{\prime} \in \bigcap f(w) \rightarrow p\left(w^{\prime}\right)\right] \text {. } \\
& \text { c. } \quad \llbracket(11) \rrbracket=\llbracket \text { obligatorily } \rrbracket(\llbracket m u s t \rrbracket)(f)(p) \\
& =\lambda w . \llbracket m u s t \rrbracket(f)(p)(w) \wedge \forall w^{\prime}\left[w^{\prime} \in \bigcap f(w) \rightarrow p\left(w^{\prime}\right)\right] . \\
& =\lambda w . \forall w^{\prime}\left[w^{\prime} \in \bigcap f(w) \rightarrow p\left(w^{\prime}\right)\right] \wedge \forall w^{\prime}\left[w^{\prime} \in \bigcap f(w) \rightarrow p\left(w^{\prime}\right)\right] \text {. } \\
& =\lambda w . \forall w^{\prime}\left[w^{\prime} \in \bigcap f(w) \rightarrow p\left(w^{\prime}\right)\right] .
\end{aligned}
$$

Thus (11), which contains two modals, ends up making one modal claim, resulting in the concording effect. We will apply the same kind of analyses to zettaini.

In addition to multiple modals being interpreted as if there is only one modal, there is another important observation around modal concord, which is the requirement that two modals that enter into a concord relation must agree in their quantificational force. For example, (12-a) sounds odd because must makes universal quantification, while the quantificational force of legitimately is existential, as represented in (12-b).

$$
\begin{aligned}
& \text { a. \#John must legitimately deny your request. } \\
& \text { b. 【legitimately } \rrbracket \lambda M \lambda f \lambda p \lambda w: f \text { is deontic. } \exists w^{\prime}\left[w^{\prime} \in \bigcap f(w) \wedge p\left(w^{\prime}\right)\right] . \\
& \text { c. Implicature of existentials: } \neg \forall w^{\prime}\left[w^{\prime} \in \bigcap f(w) \rightarrow p\left(w^{\prime}\right)\right] .
\end{aligned}
$$

(Anand \& Brasoveanu 2009: 24)

Anando \& Brasoveanu argue that the deviance is due to the incompatibility between the universal claim made by must and the implicature of the existential legitimately, the latter of which requires that not all worlds in the quantificational domain are worlds where the prejacent is true (non-universality implicature), as in (12-c). In (12-a), must requires all worlds in $\bigcap f(w)$ to be ones where John denies your request, which goes against the implicature of legitimately that John does not do so in at least one world in $\bigcap f(w)$. This inconsistency makes (12-a) deviant.

We have to add some twists to Anando \& Brasoveanu's (2009) analysis in order to capture the semantics of zettaini properly. First, as has been mentioned, zettaini shows the strengthening effect, which is not achieved if zettaini just makes a universal quantification over the same quantificational domain as the modal with which it co-occurs; (11-c) ends up asserting the same thing as John must be home, so if zettaini shared the same semantics with obligatorily, we would not expect the strengthening effect. Second, the denotation of adverbs like (11-b) only works when the modal auxiliary and adverb are clause-mates; otherwise, the two modals could not share the same contextual backgrounds. However, zettaini concords with a modal occurring in the clause embedding it:

Kono zyoohoo-o zettaini morasa-nai koto-ga gimudukera-re-teiru. this information-ACC definitely leak-NEG COMP-NOM oblige-PASS-PROG 'It is obliged that you definitely should not leak this information.'

In (13), zettaini, which is located in the complement clause, concords with the modal gimudukerare-teiru 'be obliged', which occurs in the matrix clause. This case of concord cannot be cap- 
tured with the lexical entry presented in (11-b).

Taking these two points into consideration, we propose the following semantics for zettaini. ${ }^{5}$

$$
\begin{aligned}
\llbracket \text { zettaini } \rrbracket^{a}= & \lambda f_{2} \lambda g_{2} \lambda p \lambda M \lambda w:\left[\lambda f \lambda g . \llbracket M \rrbracket^{a}\left[\begin{array}{c}
f_{1} \rightarrow f \\
g_{1} \rightarrow g
\end{array}\right]\right]\left(f_{2}\right)\left(g_{2}\right) \text { is defined. } \\
& \exists S\left[\cap f_{2}(w) \cap \operatorname{BEST}\left(f_{2}\right)\left(g_{2}\right)(w) \subseteq S \wedge \forall w^{\prime}\left[w^{\prime} \in S \in \rightarrow p\left(w^{\prime}\right)\right]\right] .
\end{aligned}
$$

Zettaini takes its own modal base $f_{2}$ and ordering source $g_{2}$. The pressupositional part of the denotation abstracts over $M$ 's modal base and ordering source and requires $f_{2}$ and $g_{2}$ to fulfill the presupposition of $M$, which in turn ensures that zettaini shares the same contextual backgrounds with the original modal claim, as in Anando \& Brasoveanu (2009). Zettaini further introduces a set of worlds $S$ that is a superset of the set of best-ranked worlds in terms of $f_{2}$ and $g_{2}$, and requires a universal quantification to hold over the new quantificational domain. The quantificational domain is larger than the ordinary modal claims, hence the strengthening effect being obtained.

Let us illustrate the derivation of the meaning of (9-a) as an example. We assume the LFstructure for $(9-a)$ as in $(15-a)$.

a. $\quad$ LF for $(9-a)$

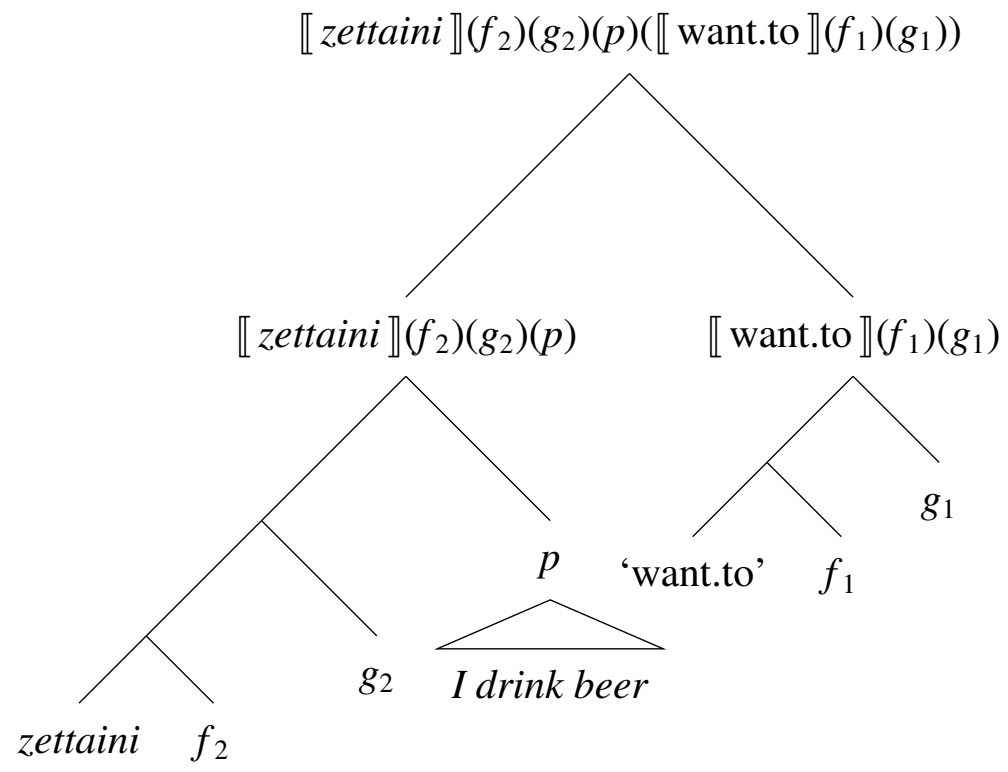

b. 【want.to $\rrbracket\left(f_{1}\right)\left(g_{1}\right)$ is defined only if $f_{1}$ is circumstantial and $g_{1}$ is bouletic.

c. Presupposition of zettaini: $\left[\lambda f \lambda g\right.$. 【want.to $\left.\rrbracket^{a}\left[\begin{array}{l}f_{1} \rightarrow f \\ g_{1} \rightarrow g\end{array}\right]\left(f_{1}\right)\left(g_{1}\right)\right]\left(f_{2}\right)\left(g_{2}\right)$ is defined.

$=\llbracket$ want.to $\rrbracket^{a}\left(f_{2}\right)\left(g_{2}\right)$ is defined.

$=f_{2}$ is circumstantial and $g_{2}$ is bouletic.

d. $\quad$ zettaini $\rrbracket^{a}\left(f_{2}\right)\left(g_{2}\right)(p)\left(\llbracket\right.$ want.to $\left.\rrbracket\left(f_{1}\right)\left(g_{1}\right)\right)$ is...

(i) defined only if $f_{2}$ is circumstantial and $g_{2}$ is bouletic.

(ii) true iff $\exists S\left[\bigcap f_{2}(w) \cap \operatorname{BEST}\left(f_{2}\right)\left(g_{2}\right)(w) \subseteq S \wedge \forall w^{\prime}\left[w^{\prime} \in S \in \rightarrow\right.\right.$ I drink beer in

\footnotetext{
${ }^{5}$ Note that unlike Anando \& Brasoveanu's (2009) notation, we treat $M$ as the variable over modals whose slots for contextual backgrounds are already saturated.
} 


$$
\left.\left.w^{\prime}\right]\right] \text {. }
$$

The contextual backgrounds for the universal modal claim made by zettaini are of the same kind as the original 'want.to'-claim, which means that the resulting sentence (15-d) is a bouleticmodal claim. Furthermore, the larger quantificational domain $S$ makes the modal claim stronger. Thus we can capture the correct meaning of zettaini-sentences with the semantics in (14). Note that (14) is applicable to cases like (13), where zettaini and the modal it modifies are not clause-mates; as is seen in (15-a), zettaini does not have to occur in the sister position of the modal that is to be modified. ${ }^{6}$

Before proceeding to the discussion of matigainaku, let us address force-agreement. As in English modal concord, zettaini shows incompatibility with possibility modals: ${ }^{7}$

$$
\begin{aligned}
& \text { \#John-wa zettaini isha kamosirenai. } \\
& \text { John-TOP definitely doctor might } \\
& \text { 'John definitely might be a doctor.' }
\end{aligned}
$$

We can derive this deviance in the same way as Anando \& Brasoveanu (2009). Let us assume that the possibility modal kamosirenai 'might' accompanies an implicature that the prejacent is not true at some worlds in its quantificational domain. This is incompatible with the assertion of zettaini, since it requires the prejacent John is a doctor to be true in all worlds in a superset of kamosirenai's quantificational domain.

4.2 Matigainaku AS A PURE EPISTEMIC MODAL. This subsection proposes that unlike zettaini, the modal flavor of matigainaku is lexically determined to be epistemic, and that it does not involve ordering source (von Fintel \& Gillies 2010). The pure epistemicity of matigainaku is seen in the following examples:

(17) a. (At a pub, John is trying to order his and your drinks. He asks you "What do you want to drink?" You say)

\#Watashi-wa matigainaku biiru-ga nomi-tai.

I-TOP certainly beer-NOM drink-want.to

'I definitely want to drink beer.'

b. (Yesterday you said an inappropriate thing to a friend. You regret it and you now have firm determination not to say such a thing. You say to yourself)

\#Watashi-wa matigainaku nidoto anna-koto-o iwa-nai.

I-TOP certainly again that-thing-ACC say-NEG

'I will certainly not say that thing again.'

Just as the epistemic auxiliary nitigainai is odd in these contexts, matigainaku also sounds awkward. This correlation indicates that matigainaku cannot encode modal flavors other than the epistemic one.

\footnotetext{
${ }^{6}$ As the reader may point out, we have to posit a covert epistemic modal in order to derive the epistemic reading of the zettaini-sentence in (1). This assumption is not unreasonable given that Japanese bare forms provide modality in some cases as we saw in footnote 4, and this problem is not specific to ours: how to deal with the cases where a concord adverb accompanies no modal but modality is detected is a challenge for any analyses in which concord adverbs do not have their own modal component.

${ }^{7}$ We thank Uli Sauerland (p.c.) for bringing out this point.
} 
Let us move onto the lack of ordering sources. It is generally assumed that epistemic necessity modals without ordering sources encode the speaker's maximal certainty of the truth of the prejacent, because the presence of ordering sources narrows down the context set, the quantificational domain for epistemic modals, to a subset of it. English must, von Fintel \& Gillies (2010) argue, encodes the maximal certainty and does not have ordering sources accordingly. The oddness of the following discourse is one of the observations supporting this claim:

A: It must be raining.

B: [Opens curtains] No it isn't. You were wrong.

A: \#I was not! Look, I didn't say it WAS raining. I only said it MUST be raining. Stop picking on me!

(von Fintel \& Gillies 2010: (19))

The deviance of A's reply indicates that she cannot avoid the blame because she has maximally committed herself to the truth of it is raining in her first utterance. Replacing must with a weaker modal like might improves the acceptability:

A: It might be raining.

B: [Opens curtains] No it isn't. You were wrong.

A: I was not! Look, I didn't say it WAS raining. I only said it MIGHT be raining. Stop picking on me!

(ibid.: (17))

The fact that the discourse sounds consistent with a weaker modal underpins the claim that the maximal certainty is at play in (18).

The same pattern holds for matigainaku and other weaker epistemic adverbs:
A: Ame-ga matigainaku futteiru. rain-NOM certainly falling 'It is certainly raining.'

B: [Opens curtains] Futtei-nai. Kimi-wa matigatteiru. falling-NEG you-TOP wrong
'It is not raining. You are wrong.'

A: \#Watasi-wa matigainaku futteiru-to itta dake-da. Futteiru-to-wa ittei-nai. I-TOP certainly falling-COMP said only-COP. falling-COMP-TOP said-NEG. 'I only said it was certainly raining. I didn't say it was raining.'

The use of a weaker adverbs like osoraku 'probably' rescues the discourse:

(21) A: Ame-ga osoraku futteiru. rain-NOM probably falling 'It is probably raining.'

B: [Opens curtains] Futtei-nai. Kimi-wa matigatteiru. falling-NEG you-TOP wrong 'It is not raining. You are wrong.'

A: Watasi-wa osoraku futteiru-to itta dake-da. Futteiru-to-wa ittei-nai. I-TOP probably falling-COMP said only-COP. falling-COMP-TOP said-NEG. 'I only said it was probably raining. I didn't say it was raining.' 
We see from these data that matigainaku encodes the speaker's maximal certainty like English must, so we can safely conclude that no ordering source is involved in its denotation. Thus we propose that (22) is the semantics of matigainaku, which is a traditional epistemic necessity modal: ${ }^{8}$

$$
\llbracket \text { matigainaku } \rrbracket=\lambda p \lambda w . \forall w^{\prime}\left[w^{\prime} \in C S(w) \rightarrow p\left(w^{\prime}\right)\right] .
$$

Before closing the section, comments on Lassiter (2016) are in order. Lassiter (2016) criticizes von Fintel \& Gillies (2010) and argues that must does not encode the maximal certainty. One of his counter arguments is that modals that are strong enough, such as $99.9 \%$ certain, are infelicitous in the same context as (18):

A: It's $99.9 \%$ certain that it's raining.

B: [Opens curtains] No it isn't. You were wrong.

A: ??I was not! Look, I didn't say it WAS raining. I only said it was 99.9\% CERTAIN that it was. Stop picking on me!

(Lassiter 2016: (55))

What this example indicates is that an epistemic modal does not have to be maximally strong to resist this context, which invalidates the claim that the oddness of (18) is evidence for must having the maximal certainty.

However, Lassiter's counterargument does not impair the validity of our proposal on matigainaku for several reasons. First, von Fintel \& Gillies (2018) are not fully certain about the oddness of (23), and they mention that setting an appropriate dialogue makes (23) sound fine:

A: It's $99 \%$ certain that it's raining.

B: [Opens curtains] No it isn't. You were wrong.

A: Well, strictly speaking, I was not wrong. I was careful. I only said it was $99 \%$ certain that it was raining.

(von Fintel \& Gillies 2018: (10))

Second, in Japanese, modals like $99.9 \%$ certain sounds felicitous in the same context as (18) without the modification done by von Fintel \& Gillies (2018):

A: Ame-ga 99.9-paasento futteiru. rain-NOM 99.9-percent falling

\footnotetext{
${ }^{8}$ As von Fintel \& Gillies (2010) and Matthewson (2015) argue, English must can only be used when the speaker's evidence is indirect, i.e., the utterance it must be raining is infelicitous if the speaker is directly seeing rain. The same observation goes for matigainaku:

(i) (Seeing falling raindrops)

\#Ame-ga matigainaku futteiru.

rain-NOM certainly falling

'It is certainly raining.'

In order to exclude examples like this, we have only to add the indirectness presupposition to (22) like the following:

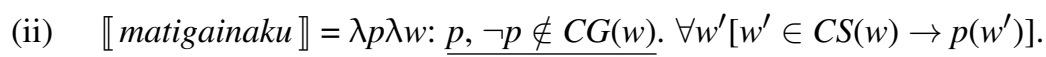

The presupposition, which is adapted from von Fintel \& Gillies (2010), requires $C G(w)$ to contain neither $p$ nor $\neg p$ as one of its members, that is, the participants to know neither that $p$ is true or that $p$ is false. This amounts to saying that the participants do not know the truth of $p$ directly. This indirectness presupposition is not relevant to the discussion to come, so we will omit this part for the sake of simplicity.
} 
'It is raining with $99.9 \%$ probability.'

B: [Opens curtains] Futtei-nai. Kimi-wa matigatteiru.

falling-NEG you-TOP wrong

'It is not raining. You are wrong.'

A: Watasi-wa 99.9-paasento futteiru-to itta dake-da. Futteiru-to-wa ittei-nai.

I-TOP 99.9-percent falling-COMP said only-COP. falling-COMP-TOP said-NEG.

'I only said it was raining with $99.9 \%$ probability. I didn't say it was raining.'

99.9-paasento, which is quite strong but not maximal, can be used in this discourse while matigainaku is not, which clearly supports the argument that matigainaku is maximally strong. Third, Lassiter focuses only on the English auxiliary must, and he observes with an experiment that the English adverb certainly is stronger than must. Matigainaku is an adverb akin to certainly, so even if his argument on must is correct, it does not immediately follow that matigainaku's strength is also non-maximal.

5. Illustration. We are now ready to illustrate how the contrast between two adverbs in (2). The meaning of the zettaini-case, repeated here as (26-a), is derived in almost the same way as (15), where zettani modifies the bouletic modal -tai:

a. Ringo-o zettaini taber-o. apple-ACC definitely eat-IMP

'Definitely eat an apple!'

b. LF for (26-a)

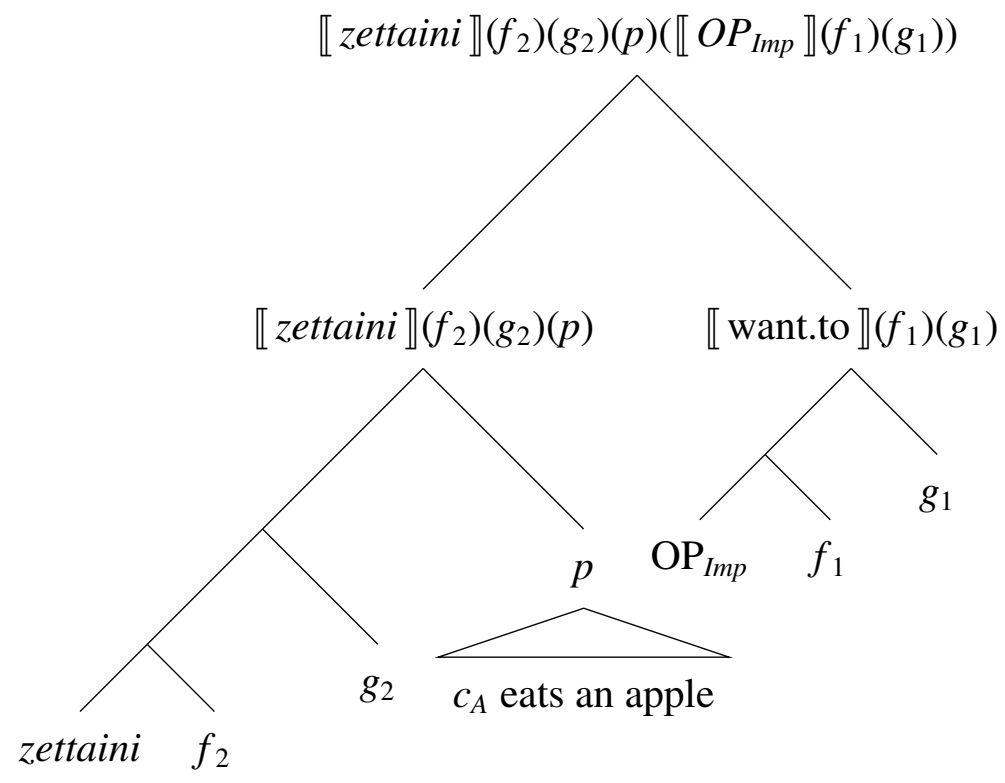

c. $\llbracket O P_{\text {Imp }} \rrbracket\left(f_{1}\right)\left(g_{1}\right)$ is defined only if $f_{1}$ is $C G$ and $g_{1}$ is deontic.

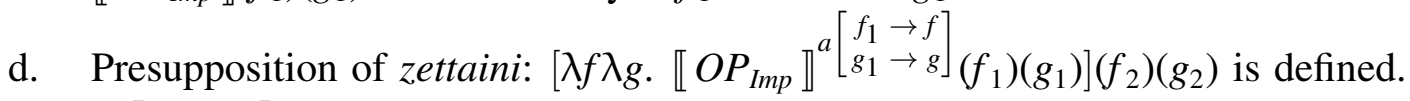

$=\llbracket O P_{I m p} \rrbracket^{a}\left(f_{2}\right)\left(g_{2}\right)$ is defined.

$=f_{2}$ is $C G$ and $g_{2}$ is deontic.

e. $\llbracket$ zettaini $\rrbracket^{a}\left(f_{2}\right)\left(g_{2}\right)(p)\left(\llbracket O P_{I m p} \rrbracket\left(f_{1}\right)\left(g_{1}\right)\right)$ is... 
(i) defined only if $f_{2}$ is $C G$ and $g_{2}$ is deontic.

(ii) true iff $\exists S\left[\bigcap f_{2}(w) \cap \operatorname{BEST}\left(f_{2}\right)\left(g_{2}\right)(w) \subseteq S \wedge \forall w^{\prime}\left[w^{\prime} \in S \in \rightarrow c_{A}\right.\right.$ eats an apple in $\left.w^{\prime}\right]$.

As in (15), the result is stronger than the plain imperative, because of the larger quantificational domain $S$.

Let us turn to the matigainaku-case, repeated here as (27-a). We assume the structure (27-b) for the LF of (27-a), and the truth-condition will be computed as in (27-c):
a. Ringo-o matigainaku taber-o.
apple-ACC certainly eat-IMP
'Certainly eat an apple.'

b. $\quad$ LF for $(27-a)$

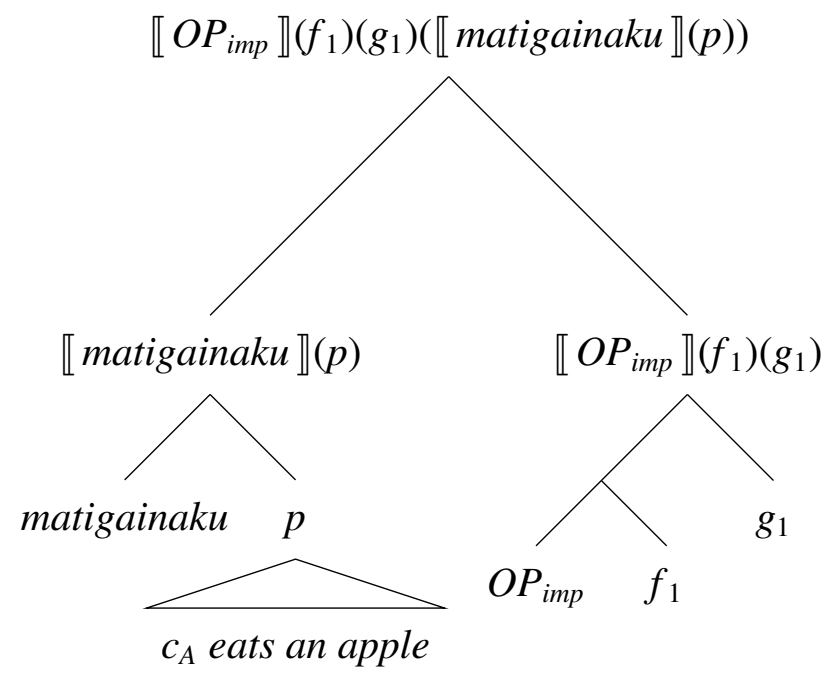

c. $\quad \llbracket O P_{\text {imp }} \rrbracket\left(f_{1}\right)\left(g_{1}\right)(\llbracket$ matigainaku $\rrbracket(p))$

$=\forall w^{\prime}\left[w^{\prime} \in \bigcap f(w) \cap \operatorname{BEST}(f)(g)(w) \rightarrow \forall w^{\prime \prime}\left[w^{\prime \prime} \in C S\left(w^{\prime}\right) \rightarrow c_{A}\right.\right.$ eats an apple in $\left.\left.w^{\prime \prime}\right]\right]$

$=\forall w^{\prime}\left[w^{\prime} \in C S(w) \cap \operatorname{BEST}(f)(g)(w) \rightarrow \forall w^{\prime \prime}\left[w^{\prime \prime} \in C S\left(w^{\prime}\right) \rightarrow c_{A}\right.\right.$ eats an apple in $\left.\left.w^{\prime \prime}\right]\right]$ $(f(w)$ is $C G(w)$, so $\bigcap f(w)=C S(w))$ $=\forall w^{\prime}\left[w^{\prime} \in C S(w) \cap \operatorname{BEST}(f)(g)(w) \rightarrow \forall w^{\prime \prime}\left[w^{\prime \prime} \in C S(w) \rightarrow c_{A}\right.\right.$ eats an apple in $\left.\left.w^{\prime \prime}\right]\right]$

(Closedness: since $w^{\prime} \in C S(w), C S(w)=C S\left(w^{\prime}\right)$ ) $=\forall w^{\prime \prime}\left[w^{\prime \prime} \in C S(w) \rightarrow c_{A}\right.$ eats an apple in $\left.w^{\prime \prime}\right]$.

(Vacuous quantification)

The two context sets involved in the formula, $C S(w)$ and $C S\left(w^{\prime}\right)$, end up being identical because of the closedness discussed in Section 3, which makes the quantification by $O P_{\text {Imp }}$ vacuous, since the variable $w^{\prime}$, which is bound by the $O P_{I m p}$ 's universal quantifier, does not appear in the second universal quantification done by matigainaku. As a result, the contribution of $O P_{\text {Imp }}$ is lost (that is, $\llbracket O P_{\text {Imp }} \rrbracket\left(f_{1}\right)\left(g_{2}\right)(\llbracket$ matigainaku $\rrbracket(p))=\llbracket$ matigainaku $\left.\rrbracket(p)\right)$, which violates the following principle:

(28) The principle of non-vacuity (Crnič 2011: 110)

The meaning of a lexical item used in the discourse must affect the meaning of its host sentence (either its truth-conditions or its presuppositions). 
Adding $O P_{\text {Imp }}$ to matigainaku(p) makes no semantic difference because the closedness leads to vacuous quantification, hence being susceptible to (28).

6. Conclusion and implication. This paper has given an account of why certain epistemic adverbs in Japanese can/cannot be embedded under imperatives. We have argued that the embeddable adverb is a modal modifier that expands the quantificational domain of the modal co-occurring with it, whereas the unembeddable one is a pure epistemic modal that ends up causing vacuous quantification and nullifies the contribution of imperative operators.

The rest of this paper shows that only the modal (or strong) theory for imperatives can capture a parallelism between imperatives and modals. As we have shown so far, the current analysis relies on a rich denotational semantics of imperatives proposed by Kaufmann (2012), according to which imperatives denote modalized propositions. As is well known in the recent studies of imperatives, however, there is a competing view proposed by Portner (2007) (See also von Fintel \& Iatridou (2017)). Portner, following Hausser (1980), rather proposes the 'minimal' denotational semantics, namely the 'non-modal' semantics, according to which imperatives denote a property (rather than a proposition) that is restricted to the addressee (as in (29)), and update a context by adding the property to the discourse component called the ToDo Lists (TDLs): for every individual, the TDL contains a list of properties that the individual should make true of themselves. For Portner, then, the heavy lifting of imperatives is done in the pragmatics: the meaning of 'necessity' that we associate with imperatives is not encoded in the syntax-semantics but is part of the relevant discourse component.

$\llbracket$ Come to the party $\rrbracket^{c}=\lambda w \lambda x: x=c_{A} . x$ comes to the party at $w$

Consider now the data in (30), repeated from (13), where matigainaku and zettaini are embedded under the deontic modal gimudukera-re-teiru '(be) obliged.' Interestingly, as in the case of imperatives, matigainaku cannot be embedded under the modal while zettaini is felicitous.

(30) Kono zyoohoo-o zettaini/\#matigainaku morasa-nai-koto-ga gimudukera-re-teiru. this information-ACC definitely/certainly leak-NEG-COMP-NOM oblige-PASS-PROG 'It is obliged that you should definitely not leak this information.'

The fact that both imperatives and performative modals can embed zettaini but cannot matigainaku constitutes a problem for any analysis of imperatives that assigns them no modals. For Portner's minimal semantics, it is difficult to capture this parallelism between imperatives and performative modals that we have shown above, because performative modals clearly denote a proposition rather than a property (and thus cannot update the TDL). It is worth noting that it is not the case that Portner's account of imperatives is 'modality-free;' he claims that the modality exists as 'meta-modality,' but just not in the syntax and semantics (the particular meta-modality involved in the TDL in a theory of context is explored in detail in Portner (2007)). We stress, however, that it is still unclear how certain epistemic adverbs like matigainaku and zettaini interact with imperatives within the theory of minimal semantics; the theory needs to be extended or at least say more about what the character of modality involved in 
the TDL is. ${ }^{9}$

On the other hand, the same explanation as in the case of imperatives can be applied to (30), which lends support for the modal view of imperatives; in (30), while zettaini can strengthen the modal claim made by the deontic modal 'it is obliged' thanks to its flexibility, matigainaku violates the non-vacuity principle since the deontic modal embedding matigainaku cannot make any contribution due to vacuous quantification.

Although the present analysis supports the modal view, it does not immediately mean that we should completely reject the minimal approach. Instead, we are claiming that at least in some language, especially in Japanese, the modal approach is clearly needed. One possibility might be whether or not imperatives contain modals depends on language-specific morphological systems (cf. Medeiros 2013); that is, for instance, imperatives in Japanese may encode modals whereas in English, imperatives may denote no modality. We should thus verify whether the account in this paper can be applied to imperatives in other languages, which will be left to future research. Moreover, examining a compatibility between 'non-canonical' form imperatives (See von Fintel \& Iatridou (2017) for Hebrew and German. See Ihara \& Noguchi (2019) for Japanese) and epistemic adverbs also needs to be implemented.

\section{References}

Anand, Pranav \& Adrian Brasoveanu. 2009. Modal concord as modal modification. In Prinzhorn, Martin, Schmitt, Viola \& Zobel, Sarah (eds.), Proceedings of Sinn und Bedeutung 14. 1936. Berlin: Zentrum fur Allgememe Sprach wissenschaft.

Condoravdi, Cleo \& Sven Lauer. 2012. Imperatives: Meaning and illocutionary force. In Christopher Piñón (eds.), Empirical issues in syntax and semantics 9. 37-58. http://www.cssp.cnrs.fr/eiss9/eiss9_condoravdi-and-lauer.pdf.

Crnič, Luka. 2011. Getting even. Cambridge, MA: MIT Ph. D. thesis.

von Fintel, Kai \& Anthony S. Gillies. 2010. Must...stay...strong! Natural Language Semantics 18(4). 351-383. https://doi.org/10.1007/s11050-010-9058-2

von Fintel, Kai \& Anthony S. Gillies. 2018. Still going strong. Ms. available at https://semanticsarchive.net/Archive/GMzZTM0Y/fintel-gillies-2018-still-Gillies

von Fintel, Kai \& Sabine Iatridou. 2017. A modest proposal for the meaning of imperatives. In Ana Arregui, María Luisa Rivero \& Andrés Salanova (eds.), Modality across syntactic categories. First edition. 288-319. Oxford: Oxford University Press.

Gillies, Anthony S. 2010. Iffiness. Semantics \& Pragmatics 3. 1-42. http://dx.doi.org/10.3765/sp.3.4 Grosz, Patrick. 2009. German particles, modality, and the semantics of imperatives. In Suzi Lima, Mullin, Kevin \& Smith Brian (eds.), Proceedings of NELS 39. 323-336. Amherst, MA: GLSA Publications.

Han, Chung-Hye. 1998. The structure and interpretation of imperatives: mood and force in universal grammar. Philadelphia, PA: University of Pennsylvania dissertation.

Hausser, Roland. 1980. Surface compositionality and the semantics of mood. In John R Searle, Ferenc Kiefer \& Manfred Bierwisch (eds.), Speech act theory and pragmatics. 71-95. Dor-

\footnotetext{
${ }^{9}$ In fact, there are problems with the TDL way of modeling the contextual effect of imperatives, many of which are canvassed by Condoravdi \& Lauer (2012).
} 
drecht and Boston: Reidel.

Ihara, Shun \& Yuya Noguchi. 2019. Imperatives with/without necessity. In Shinichiro Fukuda, Mary Shin Kim, Mee-Jeong Park \& Haruko Minegishi Cook (eds.), Japanese/Korean linguistics 25. Stanford, Calif: CSLI Publication.

Kaufmann, Magdalena. 2012. Interpreting imperatives. New York: Springer.

Kaufmann, Stefan, Cleo Condoravdi \& Valentia Harizanov. 2006. Formal approaches to modality. In Frawley William (eds.), The expression of modality. 71-106. Berlin: Mouton de Gruyter.

Kratzer, Angelika. 1983. The notional category of modality. In Hans-Jürgen Eikmeyer \& Hannes Rieser (eds.), Words, worlds, and contexts. New approaches to word semantics. 38-74. Berlin: Mouton de Gruyter.

Lassiter, Daniel. 2016. Must, knowledge, and (in)directness. Natural Language Semantics 24(2). 117-163. https://doi.org/10.1007/s11050-016-9121-8

Matthewson, Lisa. 2015. Evidential restrictions on epistemic modals. In Luis Alonso-Ovalle \& Paula Menendez-Benito (eds.), Epistemic indefinites. 141-160. Oxford: Oxford University Press.

Medeiros, David J. 2013. Formal approaches to the syntax and semantics of imperatives. Ann Arbor, MI: the University of Michigan dissertation.

Portner, Paul. 2007. Imperatives and modals. Natural Language Semantics 15. 351-383. http://dx.doi.org/10.1007/s11050-007-9022-y 